\title{
Educación Artística y prácticas contemporáneas: producir la relación con Arte, Ciencia y Tecnología
}

\author{
FERNANDO MIRANDA
}

\section{Resumen}

El artículo reflexiona sobre un proyecto de producción, desarrollo y comprensión de formas de mediación educativa, dirigido a adolescentes, a través de un programa basado en la relación Arte / Ciencia / Tecnología. Se trata de acciones que "parasitan" los contenidos de propuestas artísticas contemporáneas desarrolladas en un espacio de arte contemporáneo de la ciudad de Montevideo. Se establecen relaciones con tales contenidos -producidos por "otros", para el caso artistas y creadores visuales - para generar alternativas creativas respecto a nuevas posibilidades de significado y representación. Se propone el análisis sobre la base de una condición de laboratorio pedagógico y de mediación pública vinculada a la producción artística contemporánea, con un formato asociable a una curaduría educativa de lo expositivo desde una perspectiva de cultura visual.

Palabras-clave:

Cultura visual, práticas contemporáneas, contenidos educativos. 


\title{
Art Education and contemporary practices: producing the relationship with Art, Science and Technology
}

\author{
FERNANDO MIRANDA
}

\begin{abstract}
This paper reflects on a project of production, development and understanding of educational mediation forms, targeted to teenagers, through a program based on the relationship between Arts, Science and Technology. These are actions that "parasitize" the contents of contemporary art proposals developed in a contemporary art space in the city of Montevideo. Relationships are established with such content, produced by "others", in this case, artists and visual creators, to generate creative alternatives regarding new possibilities of meaning and representation. Analysis is proposed on the basis of a teaching laboratory condition and public mediation associated to contemporary artistic production, with a format linked to an educational curatorship of the exhibition under a visual culture perspective.
\end{abstract}

Keywords: Visual culture, contemporary practices, educational contents. 


\section{Introducción}

La continuidad de elaboración de textos, artículos y reflexiones acerca la perspectiva de la cultura visual nos remite a unas nuevas cartografías de los mapas diversos de la educación de las artes visuales. Los recorridos por estos territorios terminan por definir provisoriamente límites, espacios, zonas de refugio y también sectores de riesgo y de necesidad de nuevas alternativas a transitar.

Si la cultura es inestable, móvil, y si los sujetos se establecen en ella con raíces desarrolladas en tierras diversas, cuyas fertilidades debemos buscar, especialmente, en nuestro cometido como educadores, los desafíos son siempre renovados.

En la segunda mitad del siglo XX fuimos protagonistas o espectadores de textos de autores preocupados por los acontecimientos culturales que han definido los nuevos modos y relaciones surgidos del llamado giro de la imagen, o el giro pictorial (MITCHELL, 2009), o el giro icónico (MOXEY, 2009; AGIRRE, 2011), donde las narrativas tienen que ver con el reconocimiento del lugar de las imágenes visuales.

Esto marca, al menos, cierta autonomía de la imagen respecto a la superación de lo lingüístico como mera posibilidad de explicación y narración, de comunicación y discurso. En cualquier caso, esta suerte de superación de lo lingüístico en estos enfoques tiene que ver con el reconocimiento de la condición de lo visual y su posibilidad representacional y enunciativa.

W. J. T. Mitchell ha referido a este giro enfáticamente

Lo que quiera que sea el giro pictorial, debe quedar claro que no se trata de una vuelta a la mímesis ingenua, a teorías 
de la representación como copia o correspondencia, ni de una renovación metafísica de la 'presencia' pictórica: se trata más bien de un redescubrimiento poslingüístico de la imagen como un complejo juego entre la visualidad, los aparatos, las instituciones, los discursos, los cuerpos, la figuralidad. Es el descubrimiento de que la actividad del espectador (la visión, la mirada, el vistazo, las prácticas de observación, vigilancia y placer visual) puede constituir un problema tan profundo como las varias formas de lectura [...] (MITCHELL, 2009, p. 23)

Las consecuencias de tal descubrimiento tiene sentido, a mi juicio, en la comprensión de la experiencia estética en tanto ocurre fuera de los límites del ámbito especializado, es decir tal como sostiene Mitchell en respuesta a Boehm “...there is no doubt that a pictorial turn has also occurred at the level of popular perception, in relation to new technologies of production, distribution, and consumption of images" (BOEHM; MITCHELL, 2009, p.114)

Por esto, debemos atender las oportunidades de nuevas relaciones pedagógicas de la cultura visual como desestabilizadoras de las certezas que definen las disciplinas que los respectivos regímenes de conocimiento encuadran, y que se traducen en las formas reguladas de los sistemas educativos, las estructuras académicas de formación docente y los proyectos curriculares.

La cultura visual, en clave de fundar nuevas relaciones pedagógicas y referencias de investigación, es una oportunidad para producir movimientos desde el refugio de la solidez aparente de las disciplinas organizadas en los sistemas educativos hacia las inseguridades alternativas de condiciones posibles respecto de lo que sucede a nuestro alrededor. Es, entonces, una posibilidad para que podamos atrevernos a pedir algo más que aquello sobre lo que poseemos seguridad y evidencia tranquilizadora.

Bajo estos principios, presentamos la experiencia del proyecto "Muérdago", realizado en el Espacio de Arte Contemporáneo (EAC) ${ }^{1}$ de la ciudad de Montevideo. Este proyecto, llevado adelante por un equipo de trabajo de origen en la universidad, logró formular una alternativa educativa que relacionó la perspectiva de cultura visual, las prácticas de arte y representación contemporánea del EAC con la enseñanza secundaria en grupos de tres institutos públicos de la ciudad y la condición creativa de los estudiantes. 


\section{Consideraciones iniciales}

$\mathrm{Al}$ comienzo, una de las condiciones fundamentales que nos planteamos era trabajar con grupos de los dos últimos años de enseñanza secundaria cuyas orientaciones no estuvieran vinculadas a las artes o a las ciencias sociales, es decir, llevar adelante el proyecto con jóvenes que hubieran elegido opciones biológicas y científicas.

En Uruguay, los estudiantes de los dos últimos de Secundaria deben elegir una orientación que los ha de preparar para estudios posteriores a nivel terciario o universitario, de manera que adolescentes de dieciséis años tempranamente se ubican en sus preferencias respecto a las disciplinas del conocimiento.

Una hipótesis inicial del equipo de trabajo consideraba que los estudiantes que eligen alternativas disciplinarmente lejanas de las artes y las ciencias humanas y sociales se ubican distantes a la producción cultural y la creación, especialmente aquellas prácticas que tienen que ver con la contemporaneidad o están fuera de las formas modernas vinculadas a la pintura y la escultura fundamentalmente.

Sin embargo, nos basamos también en considerar que el proyecto podría tener éxito a partir de que existen unos saberes y conocimientos de los estudiantes que el sistema educativo no reconoce o no atiende y que podría surgir en este marco producido.

Tal como sostiene Fernando Hernández, en un texto editado recientemente en idioma catalán:

Los jóvenes tienen otros saberes, saben de otras cosas, pero al no ser oficiales, al no formar parte de la comunidad de discurso de la escuela, no son tenidos en cuenta. En este sentido, se considera que desde pequeños, el discurso de la escuela es el que les marca, porque el que no sabe lo que se pide en la escuela, queda marcado y esta señal se interioriza. (HERNÁNDEZ, 2011a, p. 11)

Para que una transformación pueda suceder, tiene que ocurrir entonces el reconocimiento de que todas las personas tienen la capacidad de representación y de producción simbólica, condiciones creativas para dar sentido al mundo, y no sólo aquellas a quien el sistema cultural reconoce y autoriza oficialmente. Por esto, la formulación referida de Mitchell (2009), supone una relación compleja entre los artefactos visuales, las imágenes, la 
Figura 1: Fotograma de video realizado por adolescentes de $5^{\circ}$ año, orientación Biológica, Montevideo. Fuente: Acervo de imágenes proyecto "Muérdago" institucionalidad que respalda la condición de esas imágenes y creaciones, y las prácticas artísticas, con la posibilidad y lugar de otros creadores, a nivel conceptual, sensible y cultural.

Desde lo educativo, y tal como surge de algunos ejemplos de desarrollo en este proyecto, debemos reconocer que el sujeto que aprende tiene una condición corporal sumamente presente y por tanto referente a la postura de que el "sujeto no es una materialización abstracta sino que está corporeizado." (PADRÓ, 2011, p. 34)

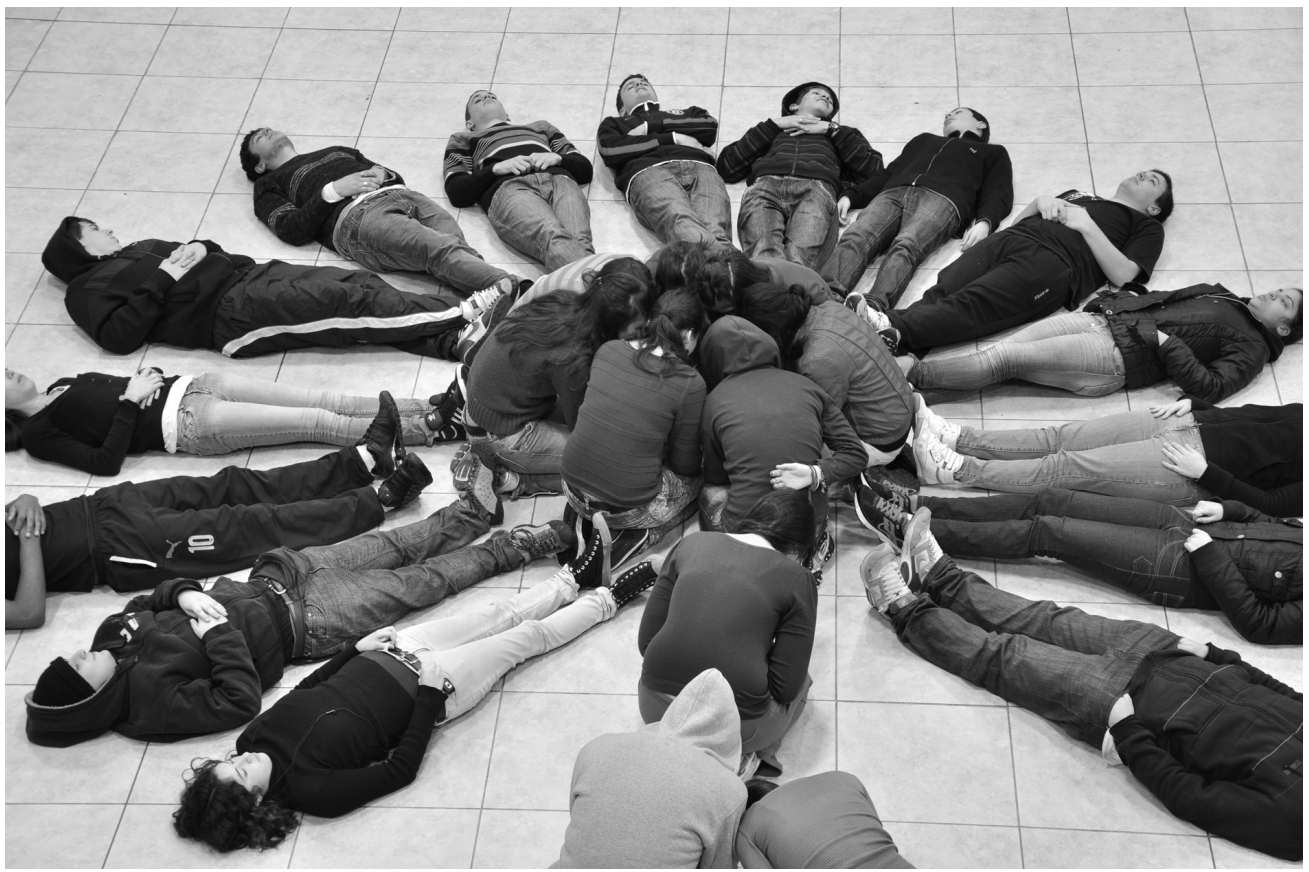

El llamado de atención para los profesores, ha de ser rescatar en las aulas el protagonismo respecto a producir y compartir las mejores formas, recursos y tecnologías para la educación de las artes visuales. De manera que, como sostiene Bourriaud tiene que ver con que:

Lo que realmente importa es lo que hacemos con los elementos puestos a nuestra disposición. Somos entonces locatarios de la cultura; la sociedad es un texto cuya regla lexical es la producción, una ley que corroen desde adentro los usuarios 
supuestamente pasivos a través de las prácticas de postproducción. (BOURRIAUD, 2007, p. 23)

El proyecto consideraba, además, que las prácticas artísticas contemporáneas habilitan nuevas formas de producción, de relaciones subjetivas y con las imágenes visuales, donde ocurren la superposición de lenguajes y medios, a favor de formas expresivas mestizas e híbridas que podrían tener la oportunidad de la transformación necesaria de la educación.

La experiencia realizada muestra las evidencias de la pretensión contemporánea que nos moviliza, en tanto reconoce la relación de las artes visuales con otras formas culturales y con distintas miradas disciplinares sociales o científicas. Espacios nuevos donde multiplicar las alternativas a ser consideradas educativamente desde la formación docente, las prácticas de creación, las experiencias personales, o la cultura visual en territorios necesariamente disciplinables tal como lo muestran, por ejemplo, autores como Fernando Hernández (2011a, 2011b).

Para esta contemporaneidad, la introducción de los estudios de cultura visual y su perspectiva educacional han generado maneras de comprender y actuar con y desde los repertorios de imágenes, acontecimientos y tecnologías visuales que construyen nuestras representaciones y construcciones de significado acerca de lo cotidiano y nuestras vidas.

Desde esta localización es posible ir más allá del conglomerado de imágenes exclusivas de las artes visuales para ubicarnos en la situación de ampliar el alcance de su acción con consecuencias teóricas y de actuación práctica.

Como sostiene Belidson Dias, y si entendemos que a partir del giro de la imagen las visualidades son articuladoras de nuestra vida diaria, hay que entender que las imágenes

se tornaron productos y objetos materiales esenciales para nuestras vidas, entonces, [...] voy a denominar el tipo de cotidiano ampliado como 'cotidiano espectacular', [...] el espectáculo es la relación social, histórica y política entre las personas mediadas por la visualidad. (DIAS, 2011, p. 67)

Estas relaciones cotidianas con las imágenes suponen que se han multiplicado sus formas de producción no profesional y que los repertorios visuales se sostienen también en el 
desarrollo de las posibilidades tecnológicas y multimediales que son la condición dominante de la época actual.

Así llegamos a que

[...] toda persona pueda ser productora y distribuidora de materiales visuales y audiovisuales de todo tipo, lo que ha desencadenado un imparable proceso de amateurización de las prácticas creativas, que estadísticamente suponen una parte muy importante de los contenidos disponibles en la red. (PRADA, 2012, p. 39)

Ya no es posible entonces abordar la educación de las artes visuales sin reconocer las influencias y la relevancia de aquel "cotidiano espectacular" desde la producción de imágenes con fines publicitarios, corporativos, comerciales, identitarios, políticos, etc.

Tampoco evadir que éstas se multiplican en soportes y formatos de distribución que trascienden fronteras físicas de pertenencia y se instalan en la construcción de identidades, a pesar de distancias geográficas, y en la cercanía y hasta intimidad de los sujetos y sus vínculos. De esta forma, lo importante es también considerar cómo en el mundo actual "las personas se interrelacionan unas con otras a través de las distancias y a través de los países." (PADRÓ, 2011, p. 128)

En la consideración del giro de época, en la espectacularidad y en la inmaterialidad de las imágenes visuales y artísticas es momento de preguntarse qué consecuencias producen esas transformaciones entre un mundo textual y un mundo audiovisual cuando nos colocamos en situaciones propias del trabajo educativo con adolescentes.

Trabajar desde la cultura visual necesita incluir la incorporación crítica de imágenes visuales, artefactos y tecnologías que constituyen las formas actuales en que, principalmente en nuestra experiencia, los adolescentes producen sus propias visualidades, procesos de identificación y explicación de la trama de relaciones circundantes con otros sujetos y con el mundo.

La visualidad es, entonces, comprendida como la forma social particular en la que nos relacionamos con las imágenes, y con otras formas de ver, incluso hasta en una condición que se nos muestra natural, cotidiana y utilitaria. A veces, hasta nos hace llegar a considerar que no existe una forma alternativa de acción.

Desde el reconocimiento de estas condiciones es que nos reunimos en esta experiencia que aquí exponemos para 
contribuir, desde el encuentro con profesores de enseñanza secundaria y adolescentes, a la comprensión y acción en la educación de las artes visuales. Si en algo sirve a lectores y lectoras nuestra intención será lograda.

\section{El proyecto “muérdago”}

Este proyecto se propuso sobre la base de una oportunidad de laboratorio pedagógico en las artes visuales y de mediación pública vinculada a la producción artística contemporánea. Su formato puede ser asociado a una curaduría educativa de lo expositivo, como dijimos, en el Espacio de Arte Contemporáneo de Montevideo.

Además, nos posicionamos en este trabajo de educación artística respecto de las prácticas contemporáneas desde la perspectiva de análisis y comprensión de la Cultura Visual y construcción de identidades diversas y relacionales del arte con respecto a otras prácticas educativas y sociales. La intención explícita es que, trabajando desde esta mirada puedan inocularse nuevas maneras y alternativas a las que aparecen naturalizadas.

Como señalamos, cuando defiendo la perspectiva de la cultura visual, lo hago considerando la importancia de la idea de visualidad en la época contemporánea, donde la presencia de las imágenes y los artefactos que operan como medios con los que las personas se relacionan cotidianamente tienen que ver con la significación, representación y narración que estas personas realizan a nivel estético, ético y social, de sus propias ubicaciones de identidad y pertenencia.

Respecto del EAC como espacio expositivo nos interesaba la producción propia de las prácticas artísticas y visuales contemporáneas, sus formas de realización, muestra y relación con la gente (sean espectadores iniciados en el tema, interesados particularmente, o personas que no tengan contactos anteriores con estas prácticas culturales).

Desde mediados del siglo XX el campo cultural ha presenciado la multiplicación de las identidades sociales y culturales, las que definen las distintas formas de narración relacionadas a las obras artísticas.

En particular, las artes visuales en sus expresiones contemporáneas han generado formas expresivas, creativas y de lenguajes que hacen complejas y confunden las modalidades tradicionales - para las que los profesores en general están entrenados-, al tiempo que borran los límites existentes con 
otras producciones de lo social. Esto marca así nuevas influencias en la comunicación, en la publicidad, en la educación, e incide en la relación cotidiana con las imágenes.

En tales circunstancias, la condición formal y las maneras analíticas en que se ha abordado la educación de las imágenes, no da cuenta ya del conjunto complejo de discursos que la producen y en los que, a su vez, colabora a promover.

La perspectiva de trabajar desde las aportaciones de los estudios de cultura visual y la educación de las artes visuales, otorga las oportunidades para que se revelen las construcciones de efecto sobre las personas.

Por tanto, desde la cultura visual es necesario ver las imágenes como enunciados de discurso más allá de su formalidad aparente, reconociendo sus potencialidades educativas y cuestionando nuestra relación con las mismas o estableciendo nuevas relaciones posibles.

Por otro lado, además, es necesario descentralizar la ocurrencia de lo artístico institucional y simbólicamente. Indagar acerca de la ocurrencia de lo visual con relación a las trayectorias biográficas de las personas que utilizan de una u otra manera las imágenes como medio de significación, representación, y comunicación, en este caso con usos y finalidades diversas a lo artístico: científicas o tecnológicas entre otras.

Por eso, la perspectiva de la pluralidad se impone en tanto no hay una forma de visualización única y probada como verdadera y se pretende la construcción de un espacio de expresión diversa y colectiva de esa pluralidad.

Respecto a las producciones artísticas y culturales, las identidades individuales y colectivas tienen relación con las formas en que las imágenes y las obras son reconstruidas por los sujetos en calidad de espectadores. Pero también los constituyen desde contenidos y referencias diferentes: especialmente estéticas, quizás, pero también sensibles, emotivas, ideológicas, conceptuales y referidas a diversos aspectos vitales cotidianos que colaboran en la experiencia.

La propuesta del proyecto "Muérdago" buscó la relación indispensable entre las forma de producción de visualidad -entre las que se encuentran las propias del arte contemporáneo-, las ubicaciones personales respecto a la ciencia y la tecnología y las condiciones de mediación estética, ética y pedagógica de la educación artística.

Nuestra mayor crítica posiblemente deba darse en que, en la educación artística vinculada a las instituciones culturales 
en general -entre las que ubicamos los museos y los centros culturales-, la influencia de la estética analítica no ha permitido colocar estos asuntos en términos de la experiencia estética sino en la formalidad del arte, en la historia y en la condición del artista como productor de obra.

La experiencia estética, tal y como la consideramos en su concepción, remite a la condición de públicos, y por ende de espacios públicos. Romper el compartimiento de las artes visuales lleva necesariamente a la condición de relación con la vida común y con diferentes entornos, en especial con los educativos.

Esos espacios públicos, incluidos los institucionales, han sido modificados radicalmente en la propia transformación de los territorios urbanos. En este sentido, las ciudades han variado sus características incorporando lo cultural como atracción y espacio de ocio, pero también como sitio en que acontezca la creación y formación ciudadana; lo que debe atender las diversas y nuevas maneras de dar respuestas a las necesidades vitales de sus habitantes.

Es necesario, ante esta situación, encontrar aquellos caminos que nos permitan un abordaje menos rígido para el análisis de la relación del público con el arte, especialmente con el arte contemporáneo. La idea de "Muérdago" buscó contravenir la imagen consolidada de la muestra de arte en el marco institucional del museo moderno, para investigar las interacciones con unos públicos plurales, en este caso adolescentes especialmente relacionados a la formación científica y tecnológica, aparentemente más alejados de las prácticas artísticas y visuales.

\section{Contexto y realización}

Por las características de desarrollo del proyecto y su propio sentido de realización, se definió finalmente la localización del mismo en tres contextos institucionales urbanos en la ciudad de Montevideo: los institutos de educación secundaria № 26, 65 y 68 .

La selección de esta localización se estableció considerando el cruce de los siguientes elementos para su definición, basados en criterios de inclusión social y diversidad:

- La distancia geográfica y accesibilidad real respecto a oportunidades de la oferta artística y cultural de la ciudad, en este caso del EAC;

- Las condiciones institucionales de pertenencia colectiva 
de los participantes, estudiantes de educación secundaria superior de opciones científicas y biológicas;

- La posibilidad de contar con referentes docentes que den respaldo a las actividades, integrándose tres docentes de comunicación visual y uno de historia del arte con aulas directas con estos grupos de adolescentes;

- Las condiciones de proyectar la experiencia más allá del presente proyecto;

- La relación de intereses y temas que puedan tener relación con las actividades artísticas seleccionadas de la temporada del EAC, vinculando tres exposiciones en curso de la temporada coincidente con el desarrollo del proyecto.

Figura 2: Imágenes de difusión de creadores y muestras seleccioFuente: Espacio de Artes Contemporáneo - Temporada 7

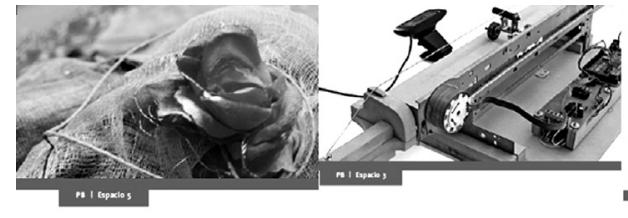

MARTIN PIÑEYRO

MARGARET WHYTE

LO QUE QUEDA

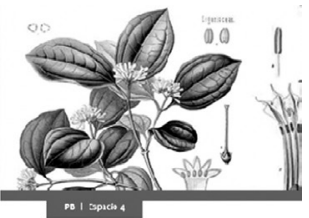

ANA PAULA RIAL JARDIN ENCANTADO

Con estos elementos nos planteamos como objetivo la intención de contribuir a la producción, desarrollo y comprensión de las formas de creación y mediación educativa respecto de las prácticas de producción artística y visual contemporáneas. Especialmente, además, considerando la relación arte - ciencia - tecnología en función de la ubicación curricular de los adolescentes participantes.

De esta forma, habríamos de producir, analizar y sistematizar prácticas de mediación educativa desarrolladas en una institución especializada -Espacio de Arte Contemporáneo-, mediante el desarrollo de un programa de educación de las artes visuales, de acuerdo a condiciones de accesibilidad educativa.

Buscamos, desde la perspectiva incorporada dar lugar a la inclusión creativa de nuevos espectadores en las actividades artísticas y culturales contemporáneas considerando la diversidad de las identidades adolescentes y proponiendo a éstos estudiantes un lugar protagónico de creación visual. 
En las opciones educativas en que los jóvenes transitan, tienen asignaturas de comunicación visual y de historia del arte, en el caso de aquellos que se orientan hacia la arquitectura, pero nuestro cometido iba más allá. Estaba dirigido a la producción de visualidades de una forma que propiciara nuevas redes de trabajo y vínculos de colaboración en las áreas disciplinares del arte, la educación de las artes visuales, las ciencias y las tecnologías. En tal sentido, se entiende que es fundamental también fortalecer la importancia que reviste la documentación como herramienta para la mediación entre las prácticas artísticas y los jóvenes y que estos puedan construir una memoria visual de sus propias producciones.

Una vez construido el escenario de participación en las instituciones y con los profesores colaboradores, se consolidó un programa de acción educativa y formación que promovería aprendizajes en torno a las prácticas vinculadas al arte contemporáneo, a punto de partida de la selección de programación señalada del EAC y la coordinación con los programas curriculares de los profesores.

El proyecto tomó el nombre de "Muérdago" por ser esta una planta parásita que vive de otras plantas. La referencia a las ciencias biológicas era inmediata y la intención era la de promover la apropiación de contenidos por los adolescentes y transformarlos en relación a sus propios intereses.

Para adolescentes que suponíamos alejados de las prácticas de creación contemporánea y del acceso a sus formas institucionalizadas se trataba de proponer la producción, el desarrollo y la comprensión de formas mediación educativa a través de un programa específico propuesto sobre la base de la relación Arte / Ciencia / Tecnología a punto de partida de "parasitar" los contenidos de las propuestas coexistentes al período de desarrollo de este proyecto. La intención era establecer relaciones con tales contenidos -producidos por "otros"- para generar alternativas creativas respecto a nuevas posibilidades de significado y representación.

Así las referencias a la tecnología y los aparatos, el trabajo con telas y material reciclado, y las referencias botánicas de las propuestas de los creadores seleccionados eran la excusa para la aproximación desde los intereses de formación de los jóvenes con los que trabajamos, ciento cincuenta estudiantes en grupos de siete a treinta y cinco, según el caso.

Los ejes de trabajo que propusimos a los profesores tenían la orientación general de la formación y la participación 
Figura 3: Muñecos con material reciclado realizados por adolescentes de $5^{\circ}$ año, orientación Científica, Montevideo. Fuente: Acervo de imágenes proyecto "Muérdago" de las personas en torno a las manifestaciones artísticas contemporáneas sobre la base de: a) las construcciones identitarias y representaciones de la adolescencia; b) las referencias institucionales y organizativas de los participantes y sus opciones de estudio y formación; c) la contribución a la formación de los profesionales que trabajan en las instituciones seleccionadas.

Sobre la selección de las muestras indicada se hubo de producir las acciones de mediación educativa en diversas localizaciones institucionales públicas. Tal selección sería la referencia y el punto de llegada sobre el cual habrían de desplegarse las acciones de formación teniendo en cuenta, como señalamos, los contenidos de aquellas que favorezcan la representación del arte en su vínculo con la Ciencia y la Tecnología.
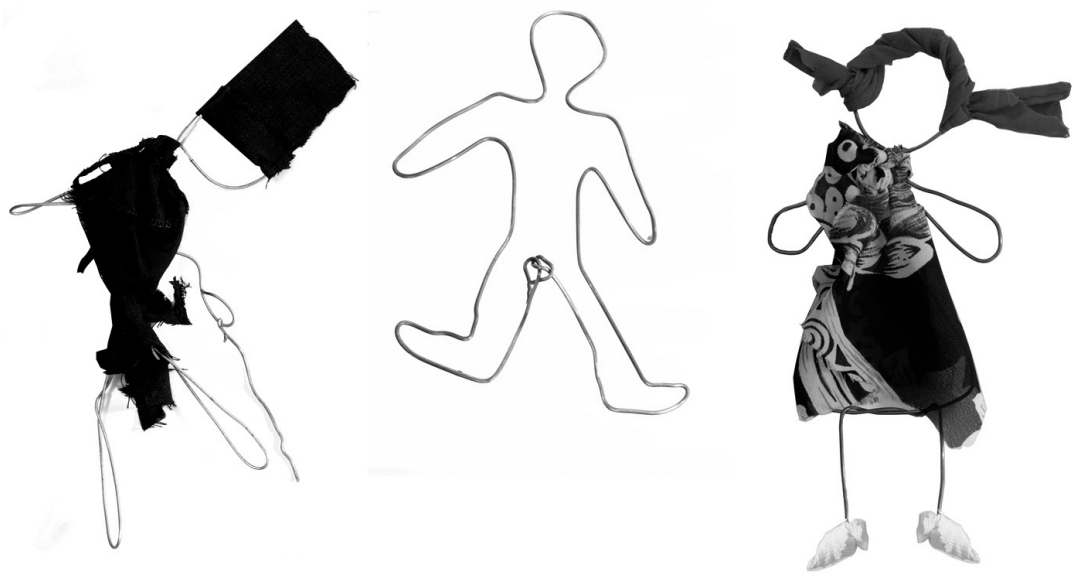

Sin embargo, para transformar las condiciones habituales la participación o visita a las salas, habría de ser el desenlace del propio programa de formación del proyecto y no el punto de partida como en general lo piensan los museos.

Sobre este criterio se realizó una fase inicial en las localizaciones originales de los participantes, en sus propias aulas con el fin de pensar y construir lugares alternativos de ocurrencia de representación de lo artístico y favoreciendo la multiplicación de la relación con las imágenes en nuevos entornos. 
Es decir, el espacio expositivo era la excusa y funcionaba como una referencia más de ocurrencia de lo artístico visual. Pero, al mismo tiempo, las actividades se localizan de manera múltiple y diversa a la centralidad institucional al desarrollarse en diferentes contextos educativos. En base a esta concepción general de trabajo se habrán de constituir las intervenciones particulares del proyecto propuesto "parasitando" los contenidos expositivos existentes.

\section{Conclusiones}

Si trabajamos en la idea y desarrollo del proyecto expuesto es porque consideramos que la educación de las artes visuales ha de tomar seriamente su relación con el arte contemporáneo y trabajar desde la perspectiva de la cultura visual y la experiencia estética.

Tal como sostiene Reyes González Vida:

[el arte] como una construcción que puede favorecer la identidad cultural del observador ya que conocer el significado de estos objetos implica conocer su valor cultural y poder interpretarlos como síntomas de cuestiones sociales y culturales a las que se vinculan [...] el arte contemporáneo es un producto sociocultural y que una de las principales características que lo definen radia en la vinculación que existe entre sus artefactos artísticos y las circunstancias políticas, sociales, económicas y culturales en que se inscribe. (GÓNZALEZ VIDA, 2007, p. 19)

Este enfoque permite que los estudiantes sean capaces de transformarse en protagonistas de la producción visual generando sus propias posibilidades de representación y construcción de significado.

En tales términos, los temas surgidos en la experiencia, si bien permiten el contracto con la producción artística contemporánea, trascienden la excusa de las obras referenciadas en el marco institucional expositivo y son reutilizadas en intenciones propias de los adolescentes y sus preocupaciones e intereses. Estas preocupaciones se ubican en temas transversales expresados fundamentalmente en torno al cuerpo, la convivencia, el consumo y los elementos de identidad. 
Figura 4: Fotogramas de animación sobre fotografías digitales realizada por adolescentes de $5^{\circ}$ año, orientación Biológica, Montevideo.

Fuente: Acervo de imágenes proyecto "Muérdago"

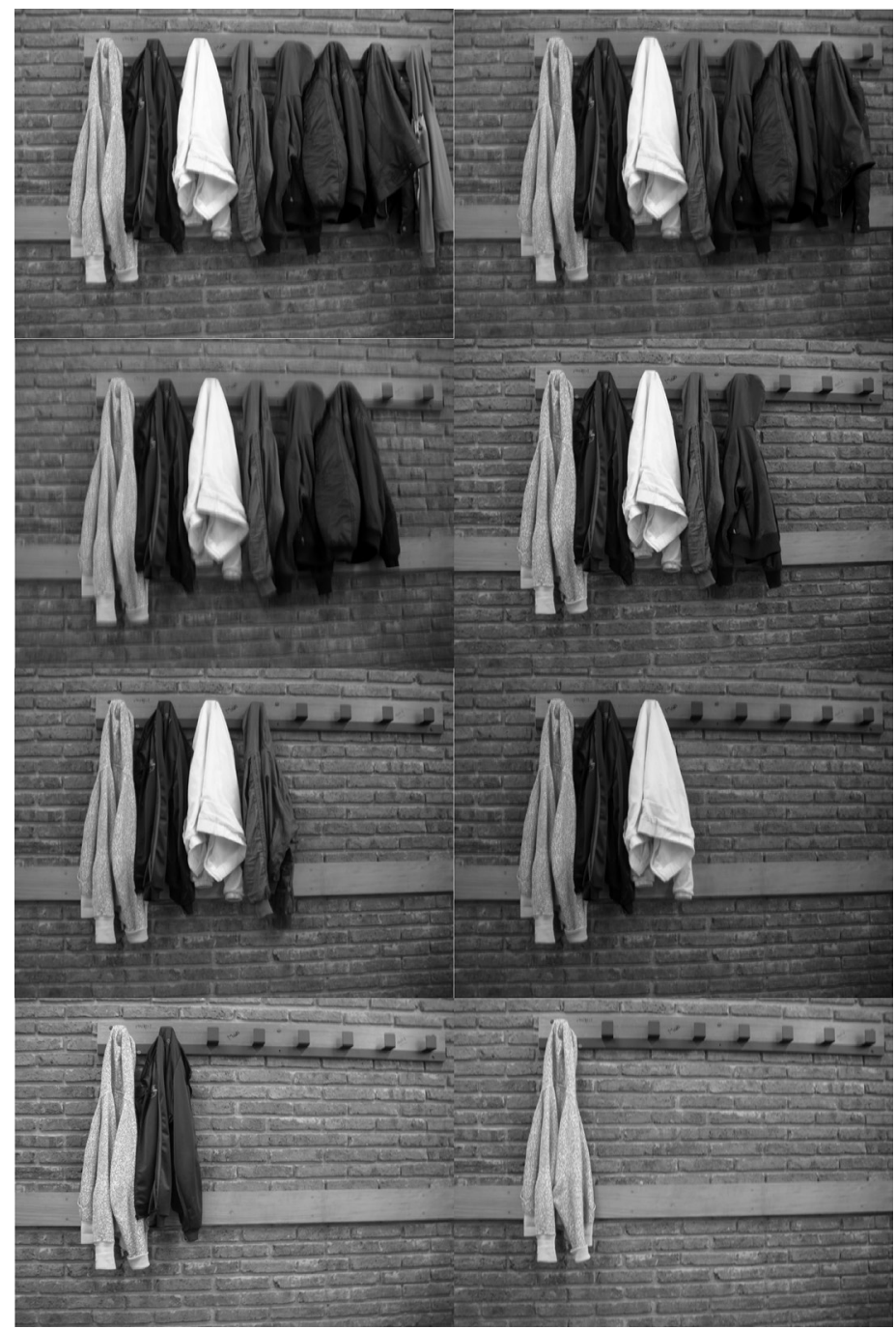

Por esto, y tal como sostiene Rancière:

La situación del arte hoy en día podría constituir perfectamente una forma específica de una relación mucho más general entre la autonomía de los lugares reservados al arte y aparentemente todo lo contrario: la implicación del arte en la constitución de la vida en común." (RANCIÈRE, 2005, p. 20) 
En el mismo sentido, las prácticas artísticas contemporáneas despliegan nuevas formas de producción, no ya exclusivamente colocadas en el objeto de arte, sino en la generación de situaciones de relaciones que provocan relaciones diversas con los espectadores, modificando las consecuencias pedagógicas de las imágenes.

Tal y como expresa Fernando Hernández, la relación pedagógica

se articula como un proceso que refleja un encuentro que por incierto se inscribe en la esfera de lo posible. Por tanto, es un encuentro que afecta (de algún modo) a nuestro sentido de ser estudiantes y profesores, a ellos y a nosotros. De todos los que participan en el tejido de relaciones,... también por parte de aquellos que por alguna razón se desvinculan de lo que podía haber sido y no llegó a ser. Porque la relación pedagógica tiene que ver con el deseo, no sólo de aprender, sino de ser,... juntos y en reciprocidad. (HERNÁNDEZ, 2011b, p. 16)

La educación de las artes visuales, desde la cultura visual, debe considerar el potencial pedagógico de estas nuevas relaciones e inscribirlo en alternativas viables no para producir nuevos cánones sino para permitir alternativas que ubiquen a los estudiantes en la posibilidad de la representación y la creación de sus propias narrativas.

\section{Referencias}

AGIRRE, Imanol. Cultura visual, política da estética e educaçao emancipadora. In: MARTINS, Raimundo; TOURINHO, Irene (Orgs.) Educaçao da cultura visual. Conceitos e contextos. Santa María: Editora UFSM, 2011. p. 69-111.

BOEHM, Gottfried.; MITCHELL, William J.Thomas. Pictorial versus Iconic Turn: Two Letters In: Theory \& Critique, 2009, 50(2-3), p. 103-121.

BOURRIAUD, Nicolas. Postproducción. Buenos Aires: Hidalgo Editorial, 2007.

DIAS, Belidson. O i/mundo da educaçao da cultura visual. Brasilia: Editora de pósgraduaçao em arte da Universidade de Brasilia, 2011.

GONZÁLEZ VIDA, María de los Reyes Arte contemporáneo y construcción identitaria en Educación Infantil. Un estudio 
sobre el uso del arte contemporáneo y la construcción de la identidad cultural en el grupo Verde de la Escuela Alquería. Tesis doctoral no publicada. Granada: Universidad de Granada, 2007. Disponible en: http://digibug.ugr.es/handle/10481/1878. Último acceso 15/2/2013

HERNÁNDEZ, Fernando (Coord.) Cap a una escola secundària inclusiva: sabers $i$ experiències de joves en situació d'exclusió ESBRINA - RECERCA. Núm.5 Barcelona, 2011. Disponible en: http://hdl.handle.net/2445/15963 Último acceso 15/2/2013.

. Pensar la relación pedagógica en la universidad des-

de el encuentro entre sujetos, deseos y saberes. Barcelona: Universitat de Barcelona, 2011b. Disponible en: http://hdl. handle.net/2445/20946 Último acceso 15/2/2013.

MITCHELL, William J. Thomas.Teoría de la imagen. Madrid: Akal / Estudios Visuales, 2009.

MOXEY, Keith. Los estudios visuales y el giro icónico Estudios Visuales (6), p. 8-27 Disponible en http://www.estudiosvisuales.net/revista/pdf/num6/moxey_EV6.pdf Último acceso 15/2/2013.

PADRÓ, Carla. El aprendizaje de lo inesperado. Madrid: Los Libros de la Catarata, 2011.

PRADA, Juan Martín. Prácticas artísticas e internet en la época de las redes sociales. Madrid: Akal / Arte Contemporáneo, 2012.

RANCIÈRE, Jacques. Sobre políticas estéticas. Barcelona: UAB / MACBA, 2005.

NOTA

1 http://www.eac.gub.uy/

Recebido em: 07/10/2013

Aceito em: 08/ 11/2013 
FERNANDO MIRANDA

fmiranda68@gmail.com

Profesor del Instituto "Escuela Nacional de Bellas Artes" de la

Universidad de la República (Montevideo - Uruguay)

Coordina el Núcleo de Investigación en "Cultura Visual, Educación

Construcción de Identidad". 